\title{
Toward Management Consensus for Diplopia in Blow-Out Fractures of the Orbit
}

\author{
${ }^{1}$ Faaiz Alhamdani, ${ }^{2}$ Ian Corbett \\ ${ }^{1}$ BDS, MSc, PhD, Lecturer, Oral and Maxillofacial Department, \\ College of Dentistry Almustansiriya University-Baghdad/Iraq \\ faaizalhamdani@yahoo.com \\ ${ }^{2}$ BDS, BSc, PhD, FDS (OS) RCS, Consultant Oral Surgeon and Honorary Senior Lecturer Oral and \\ Maxillofacial Department, School of Dental Sciences-Newcastle University-Newcastle upon \\ Tyne/UK
}

\begin{abstract}
Although making a decision for the need for surgical correction of diplopia in blow-out fracture is difficult, it is logical to assume that an effective approach for management of diplopia in this type of injury should consider more than one factor. These factors include a preoperative BSV score and of the level of tissue herniation.

Recently, the authors published two papers based on 10 year retrospective data on the influence of both preoperative BSV score and orbital tissue herniation on diplopia outcome. It is possible, on the basis of these studies data, to provide a figure about the potential benefit of surgery. Surgical intervention would be more beneficial for cases with orbital muscle entrapment / muscle herniation with preoperative BSV score $\leq 60 \%$. Conservative management might be considered for cases with BSV $\geq 80 \%$. In the $60-80 \%$ BSV range, the level of tissue herniation may advise the need for surgical intervention.
\end{abstract}

Keywords: Blow-out fracture of the orbit, diplopia, surgical management protocol.

Diplopia plays a major role in blow-out fractures of the orbit management dilemma [1]. There have been three suggested causes, as discussed in the literature for diplopia: direct musculo-fascial complex injury [2,3]; orbital tissue involvement in the fracture defect [4, 5]; and Oculomotor nerve injury [6].

The aim of surgery for blow-out fracture is to restore a full field of functional binocular single vision [7]. This is usually achieved through releasing of the herniated or entrapped orbital tissue in the fracture defect. However, tissue involvement in orbital blow out fracture is not the only influential factor on ocular motility. Accordingly, the outcome of surgery might be unpredictable, as the extent of orbital tissue damage at the time of injury may not be readily determined.

Although making a decision as for the need for surgery in blow out fracture is difficult [8], it is logical to assume that an effective approach for management of diplopia in this type of injury should consider more than one factor. These factors include a preoperative BSV score and of the level of tissue herniation. Recently, the authors published two papers based on 10 year retrospective data. In the first study they found that preoperative BSV score has an important prognostic value in term of postoperative diplopia score and subjective diplopia outcome. This study also showed that patients with BSV $>80 \%$ score do not benefit from surgery, while patients with BSV $<60 \%$ benefit from surgery more than other BSV categories in terms of BSV improvement (Figuer 1) [9].

Surgery aims to restore single vision through restoring the normal position of the herniated or entrapped orbital tissue, as such, it worth considering the influence of tissue involvement on binocular vision. It appears from the second published study data (Figure 2), that orbital fat herniation, which forms about half of the cases with surgical intervention, has no significant influence when compared to no tissue herniation in relation to diplopia and ocular motility [10]. It is logical to suggest decreasing the number of surgical interventions according to this finding.

It may be difficult on the basis of available studies' data to suggest definitive guide for the management of blow-out fractures of the orbit. It is possible, however, to provide a figure about the potential benefit of surgery for different levels of preoperative BSV score: Surgical intervention would be more beneficial in terms of postoperative BSV scores for cases with orbital muscle entrapment / muscle herniation with preoperative BSV score $\leq 60 \%$. Conservative management might 
be considered for cases with $\mathrm{BSV} \geq 80 \%$ even with orbital muscle herniation. In the $60-80 \% \mathrm{BSV}$ range, the level of tissue herniation may advise the need for surgical intervention.

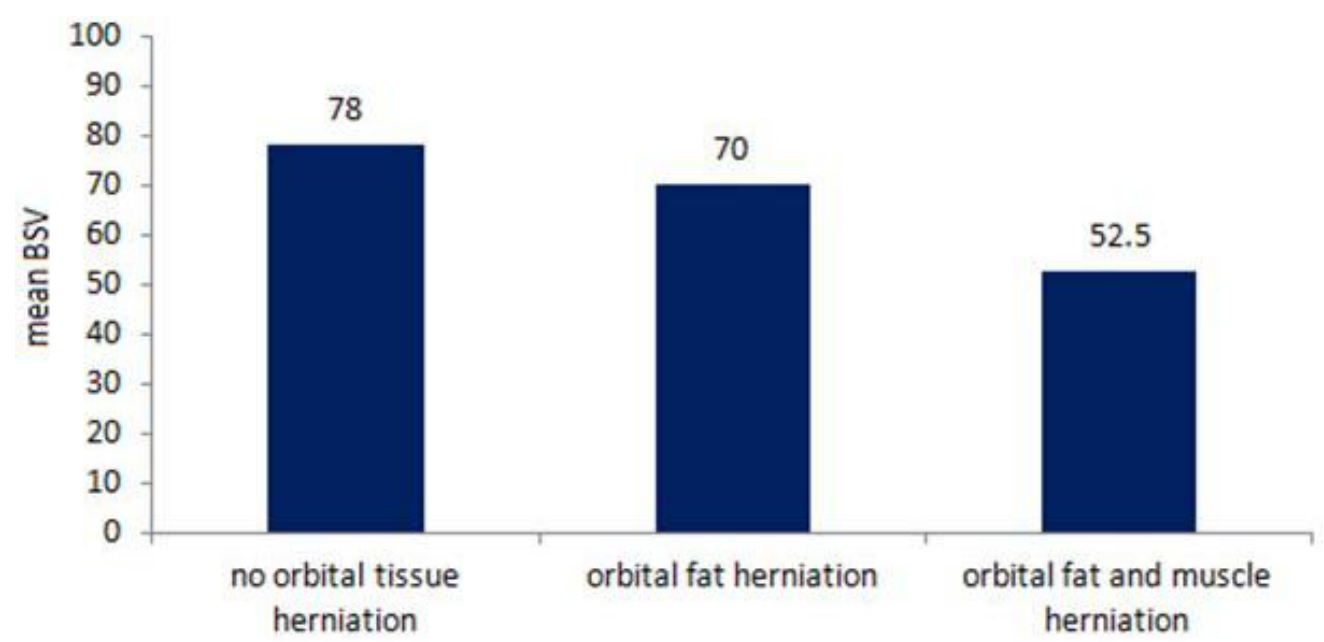

Figure1. Improvement in mean score for the three (low, middle and high) BSV score categories in the surgical group

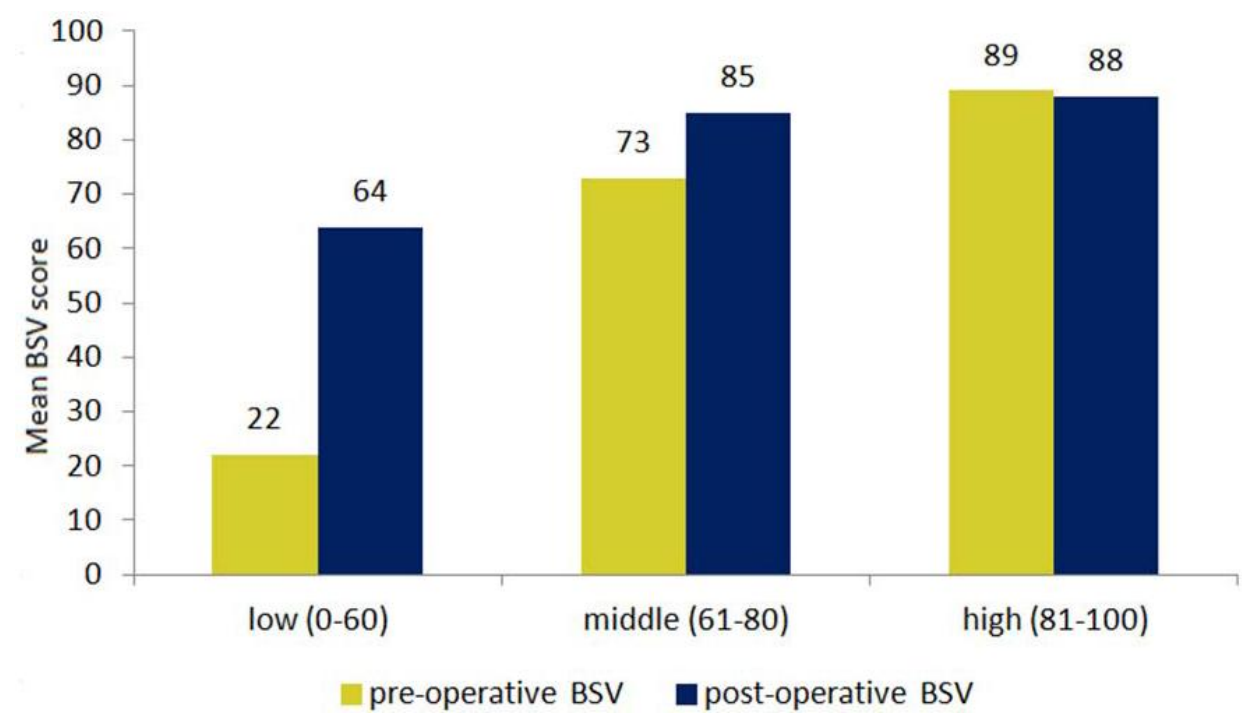

Figure2. Mean BSV score for the three levels of tissue herniation

\section{ACKNOWLEDGMENT}

This short communication paper represents the articulation of findings of two recently published articles by the authors. These papers were part of $\mathrm{PhD}$ thesis project funded by Almustansiria University and sponsored by NHS and Newcastle University.

\section{REFERENCES}

[1] Harris, G.J., Orbital blow-out fractures: surgical timing and technique. Eye, 2006. 20(10): p. 1207-12.

[2] Gosse, E.M., et al., Blow-out fractures: Patterns of ocular motility and effect of surgical repair. Br J Oral Maxillofac Surg, 2010. 48(1): p. 40-3.

[3] Huerva, V., A.J. Mateo, and R. Espinet, Isolated Medial Rectus Muscle Rupture after a Traffic Accident. Strabismus, 2008. 16(1): p. 33-37.

[4] Gilbard, S.M., et al., Orbital blowout fractures. The prognostic significance of computed tomography. Ophthalmology, 1985. 92(11): p. 1523-8.

[5] Harris, G., et al., Orbital blow-out fractures: correlation of preoperative computed tomography and postoperative ocular motility. Trans Am Ophthalmol Soc, 1998. 96: p. 329-47.

[6] Iliff, N., et al., Mechanisms of extraocular muscle injury in orbital fractures. Plast Reconstr Surg, 1999. 103(3): p. 787-99. 
[7] Carroll, S.C. and S.G. Ng, Outcomes of orbital blow-out fracture surgery in children and adolescents. Br J Ophthalmol, 2010. 94(6): p. 736-9.

[8] Mathog, R.H., Discussion: Relationship between the Extent of Fracture and the Degree of Enophthalmos in Isolated Blowout Fractures of the Medial Orbital Wall. J Oral Maxlllofac Surg, 2000. 58: p. 620-621.

[9] Alhamdani, F., et al., Diplopia and ocular motility in orbital blow-out fractures: 10-year retrospective study. J Craniomaxillofac Surg, 2015. 43(7): p. 1010-6.

[10] Alhamdani, F., et al., The influence of tissue herniation on diplopia and ocular motility in orbital blowout fractures. Oral Surgery, 2015. 8(2): p. 78-82. 